\title{
CompIMAGE'14 - computational modeling of objects presented in images: fundamentals, methods and applications
}

\author{
João Manuel R. S. Tavares
}

To cite this article: João Manuel R. S. Tavares (2016) CompIMAGE'14 - computational modeling of objects presented in images: fundamentals, methods and applications, Computer Methods in Biomechanics and Biomedical Engineering: Imaging \& Visualization, 4:2, 45-45, DOI: 10.1080/21681163.2015.1081081

To link to this article: http://dx.doi.org/10.1080/21681163.2015.1081081

\section{曲 Published online: 15 Nov 2015.}

Submit your article to this journal $₫$

\section{Џ Article views: 13}

Q View related articles $\longleftarrow$

View Crossmark data〔 


\section{EDITORIAL}

\section{CompIMAGE'14 - computational modeling of objects presented in images: fundamentals, methods and applications}

The 4th CompIMAGE conference (http://jessicaz.me.cmu.edu/ Complmage2014/) - Computational Modeling of Objects Presented in Images: Fundamentals, Methods, and Applications (CompIMAGE'14) was held in Pittsburgh, PA on 3-5 September 2014. It aimed to bring together researchers in the area of computational modelling of objects represented in images. Different approaches, such as level set method, deformable models, optimisation, geometric modelling, principal component analysis, stochastic methods, machine learning and fuzzy logic and so on, were discussed by the experts to face with problems from different applications, including medicine, biomechanics, biometrics, material science, robotics, surveillance and defence. It was the 4th edition of the CompIMAGE conferences. The previous CompIMAGE conferences were held in Rome (2012), Buffalo (2010) and Coimbra (2006).

ComplMAGE'14 invited submission of high-quality papers on broad topics including, but not limited to: medical/biological imaging, 2D and 3D reconstruction, image processing and analysis, image segmentation, data interpolation, registration and acquisition, objects tracking, motion and deformation analysis, shape modelling, simulation, scientific data visualisation, biometric person identification, visual data mining and knowledge discovery, vision in robotics and automation, material science and satellite data. There were a total of 54 submission and all the papers were reviewed by two or more members from our scientific committee which consists of 76 expert researchers from recognised institutions. In the end, we accepted 29 full papers, 10 short or position papers and 10 posters. These papers were submitted from 12 countries, including Algeria, Belgium, Brazil, China, Egypt, France, India, Italy, Portugal, Russian, Spain and USA.

There were a total of 6 keynote lectures, 8 sessions (39 paper presentations) and 1 poster session (10 poster presentations) in this conference. In particular, Professor Michael Sacks from The University of Texas at Austin talked about 'On Development of an Anatomical, Structural, and Mechanical Integrated Model of the Mitral Valve'; Professor Jelena Kovačević from Carnegie Mellon University talked about 'Problems in Biological Imaging: Opportunities for Signal Processing'; Professor Andrew D. McCulloch from University of California San Diego talked about 'Multi-Scale Image-Based Modeling of the Failing Heart: From Cell to Patient'; Professor Ross Whitaker from University of Utah talked about'Adaptivity and Conformity in Meshing: A Two Phase Strategy'; Prof. Jiun-Shyan (JS) Chen from University of California San Diego talked about 'Image Based Modeling of Biomaterials Based on Galerkin and Collocation Meshfree Method'; and Professor Marc Thiriet from Université Pierre et Marie Curie - Paris 6 (UPMC), France talked about'A Predictive Mathematical Model of Acupuncture Based on an Explanation Biological Model.'

The proceedings book was published by Springer in Lecture Notes in Computer Science (www.springer.com/Incs). Among these 39 paper presentations, we invited submission of extended versions and finally accepted 7 papers for this special issue. All the invited papers went through the required peer-review procedure by the Taylor \& Francis journal: Computer Methods in Biomechanics and Biomedical Engineering: Imaging \& Visualization. We would like to thank the authors, the reviewers, the attendances of the conference, and the publishing staff for their best effort to ensure the high quality of this special issue.

\section{ORCID}

Yongjie Jessica Zhang (iD http://orcid.org/0000-0001-7436-9757

João Manuel R. S. Tavares (iD http://orcid.org/0000-0001-7603-6526

Yongjie Jessica Zhang (iD Department of Mechanical Engineering, Carnegie Mellon University, USA @jessicaz@andrew.cmu.edu

João Manuel R. S. Tavares (iD Departamento de Engenharia Mecânica Faculdade de Engenharia, Universidade do Porto, Portugal 